Review

\title{
Uncoupling mechanism and redox regulation of mitochondrial uncoupling protein 1 (UCP1)
}

\author{
Petr Ježek ${ }^{\mathrm{a}, 1}$, Martin Jabůrek ${ }^{\mathrm{a}}$, Richard K. Porter ${ }^{\mathrm{b}, *}$ \\ ${ }^{\text {a }}$ Department of Mitochondrial Physiology, No. 75, Institute of Physiology of the Czech Academy of Sciences, Prague, Czech Republic \\ ${ }^{\mathrm{b}}$ Trinity Biomedical Sciences Institute, Trinity College, Dublin, Ireland
}

\section{A R T I C L E I N F O}

\section{Keywords:}

Mitochondrial uncoupling protein1

UCP1

Fatty acid cycling

Brown adipose tissue

Redox regulation

\begin{abstract}
A B S T R A C T
Brown adipose tissue (BAT) and brown in white (brite) adipose tissue, termed also beige adipose tissue, are major sites of mammalian nonshivering thermogenesis. Mitochondrial uncoupling protein 1 (UCP1), specific for these tissues, is the key factor for heat production. Recent molecular aspects of UCP1 structure provide support for the fatty acid cycling model of coupling, i.e. when UCP1 expels fatty acid anions in a uniport mode from the matrix, while uncoupling. Protonophoretic function is ensured by return of the protonated fatty acid to the matrix independent of UCP1. This mechanism is advantageous for mitochondrial uncoupling and compatible with heat production in a pro-thermogenic environment, such as BAT. It must still be verified whether posttranslational modification of UCP1, such as sulfenylation of Cys253, linked to redox activity, promotes UCP1 activity. BAT biogenesis and UCP1 expression, has also been linked to the pro-oxidant state of mitochondria, further endorsing a redox signalling link promoting an establishment of pro-thermogenic state. We discuss circumstances under which promotion of superoxide formation exceeds its attenuation by uncoupling in mitochondria and throughout point out areas of future research into UCP1 function.
\end{abstract}

\section{Introduction}

During the process of oxidative phosphorylation, a protonmotive force $(\Delta \mathrm{p})$, consisting of two theoretical components, electrical potential difference $\left(\Delta \Psi_{\mathrm{m}}\right)$ and proton chemical potential difference (expressed as $\Delta \mathrm{pH}$ ), is established across the inner mitochondrial membrane (IMM). Peter Mitchell's chemiosmotic theory clearly demonstrated that $\Delta \mathrm{p}$ is formed by the pumping of protons by the respiratory chain complexes, whereas $\Delta \mathrm{p}$ is consumed by the proton backflow via the $\mathrm{F}_{\mathrm{O}}$ moiety of the ATP synthase and by the $\Delta \Psi_{\mathrm{m}^{-}}$and $\Delta \mathrm{pH}$-dependent substrate or ion translocation and enzyme-dependent processes (e.g. nucleotide transhydrogenase). Balance between $\Delta \mathrm{p}$ formation and consumption by the ATP synthase is termed coupling. In contrast, uncoupling describes the situation when additional $\mathrm{H}^{+}$ backflow exists, consuming $\Delta \mathrm{p}$ without providing ATP, transport, or enzymic reaction [1]. The futile cycling of protons being pumped across the IMM followed by the short-circuit, that is the proton backflow across the IMM, results in heat production.

A diffusion based, $\Delta \mathrm{p}$-dependent, basal proton backflow determined by the inherent permeability of IMM is termed proton leak [2,3]. Specialized mitochondrial uncoupling proteins (UCPs), with tissue specific expression, provide an additional and regulable "proton leak" $[4,5]$. This latter UCP catalyzed proton leak is regulated by levels of expression of the UCP, purine nucleotides, free fatty acids and possibly by posttranslational modification of the UCPs [6-10]. The focal point of this review is uncoupling protein 1 (UCP1), the archetypal uncoupling protein. UCP 1 is primarily associated with brown adipose tissue (BAT) and is the best characterized of the UCPs. Importantly, of the UCPs, UCP1 seems unique in its thermogenic role. When active, UCP1 leads to non-shivering thermogenesis in BAT [11-15] and in beige adipocytes (also termed "brown in white", i.e. brite adipocytes), the latter being located within non-thermogenic white adipose tissue (WAT) [16-20].

Over the decades, however, several lines of enquiry have been developed to explain the uncoupling ability of UCP1. A simple view would

\footnotetext{
Abbreviations: GSH GSSG, reduced, oxidized glutathione; HIF, hypoxia-induced factor; iPLA2 $\gamma$, calcium-independent phospholipase A2 $\gamma$; NOS, nitric oxide syn-

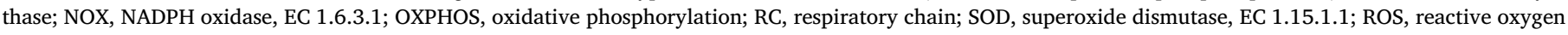
species

* Corresponding author at: School of Biochemistry \& Immunology, Room 6.08, Trinity Biomedical Sciences Institute, Trinity College Dublin, Pearse Street, Dublin 2 (D02R590), Ireland.

E-mail addresses: jezek@biomed.cas.cz (P. Ježek), rkporter@tcd.ie (R.K. Porter).

${ }^{1}$ Dept. No.75, Mitochondrial Physiology, Institute of Physiology, Academy of Sciences of the Czech Republic, Vídeňská 1083, 14,220 Prague 4, Czech Republic.
} 
be that the uncoupling, and thus thermogenic capacity of UCP1 is due simply to its abundance in a tissue [4]. However, when UCP1 was overexpressed in tissues other than BAT, such as in the heart [21], it did not uncouple mitochondria nor did it facilitate heat production. The major reason for this lack of uncoupling seems to be inhibition of UCP1 activity by purine nucleotides. UCP1, like the other UCPs, contains an outer facing cavity, and occupation of that site with purine nucleotide di- and triphosphates, in the absence of $\mathrm{Mg}^{2+}$, results in UCP1 inhibition [22-27]. Thus, early studies of BAT and brown adipocytes recognized the specific "thermogenic" environment of this tissue and its mitochondria [28-31]. This specific "thermogenic" environment consists not only of having i) UCP1 expressed in rather high amounts [5], but also ii) diminished amounts of ATP-synthase [32,33] iii) appropriate metabolic pathways to yield reducing equivalents [34], iv) the existence of a specific information signalling pathways [35] and $v$ ) adequate biogenesis of BAT [36]. In this review, we aim to summarize the properties of UCP1 common to other UCPs plus the intracellular conditions required for thermogenic mitochondrial function. We will also briefly comment on recent advances in the mechanism of activation of UCP1 and the role played by redox signalling in that mechanism and in biogenesis of BAT.

\section{Uncoupling mechanism of mitochondrial uncoupling protein UCP1}

\subsection{Fatty acid cycling mechanism}

When it comes to the fundamentals of bioenergetics, a pertinent question arises in relation to UCPs, which is, how much of the protonmotive force $(\Delta \mathrm{p})$ has to be dissipated in order to release sufficient heat to raise the temperature of BAT or other tissues? One may also ask whether the other UCP isoforms possess the ability to dissipate $\Delta \mathrm{p}$ below such a threshold? In looking for the answer to these questions, we should recall the experiments reporting the kinetic range over which UCP1 uncoupling in BAT mitochondria occurs, that being between $220 \mathrm{mV}$ and $166 \mathrm{mV}$, a range of $\sim 55 \mathrm{mV}[37,38]$. UCP2 has also been demonstrated to catalyze a regulable "proton leak" and significant UCP2 protein is expressed in spleen, lung, stomach, white adipose tissue and immune cells [5]. In contrast to UCP1, estimates for the maximal uncoupling range for UCP2 in lung mitochondria were $12.5 \mathrm{mV}[37,38]$. The maximum activity of UCP1 has been evaluated as $20 \mu \mathrm{molH}^{+} / \mathrm{min}$ per mg UCP [39-41]; i.e. $333 \mathrm{nmol} \mathrm{H}^{+} / \mathrm{s} \mathrm{per} \mathrm{mg} \mathrm{UCP,}$ which is equal to a turnover number of $11 \mathrm{~s}^{-1}$. Reconstitution of UCP2 into liposomes and black lipid membrane (BLM) show a similar $V_{\max }$ for UCP2 as for UCP1 $[42,43]$. Given the fact that UCP2 abundance is two orders of magnitude lower than that of UCP1, the range over which UCP2 uncouples reflects the relative abundance of UCP2. In conclusion, the amount of uncoupling protein within a thermogenic/non-thermogenic tissue is crucial to thermogenic capacity. However, UCP activity is also a factor.

Thermogenesis in BAT has been linked to metabolism of fatty acids (FAs) and early studies also recognized that FAs are obligatory for the activity of UCPs studied in proteoliposomes [40,41,44-46] and in BLMs $[43,47]$. This absolute requirement of FAs for UCP function has also recently been confirmed for UCP1 in patch-clamping experiments on IMM of BAT mitochondria [48].

In order to explain the mechanism of UCP1 action, the FA cycling hypothesis was originally proposed by Skulachev [49] and modeled in detail by Garlid and co-workers [39,46,50,51]. Since then the FA cycling model has been supported by numerous experiments and the structural basis for the model, i.e. namely the proposed evidence for the existence of the peripheral FA binding sites, has been supported by several laboratories $[27,52,53]$. Furthermore, the FA cycling hypothesis concept is clearly supported by the existence of synthetic small molecules - uncoupling protein mimics, which are able to perform FA-activated $\mathrm{H}^{+}$translocation in phospholipid bilayers [54]. There is also a

\section{A \\ Fatty acid cycling}

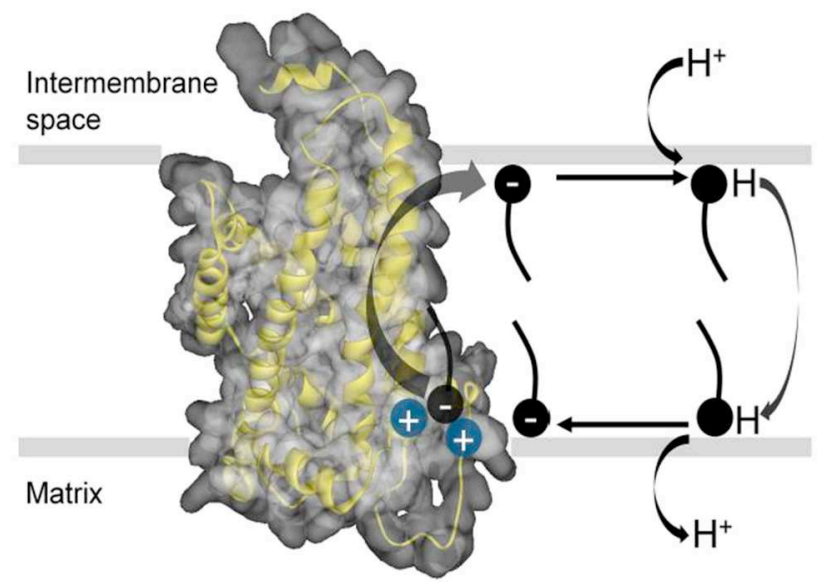

B Fatty acid shuttling-carrier

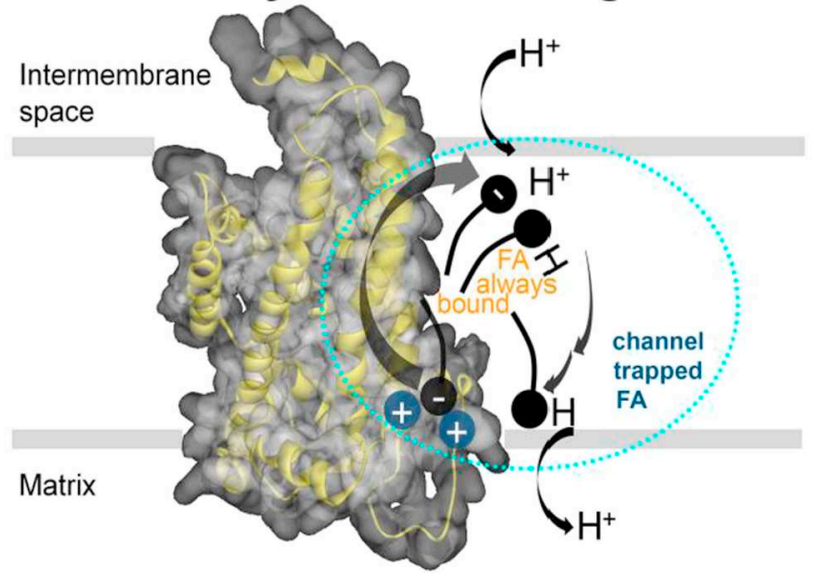

Fig. 1. UCP1 as a fatty acid anion uniporter.

A) Fatty acid cycling mechanism - The UCP-catalyzed protonophoretic cycle represents the most plausible mechanism of function for all UCPs [55]. Fatty acid (FA) anions diffuse laterally within the membrane to reach a subsurface peripheral binding site on UCP1 near the matrix [61] where it binds specifically to basic residues (depicted as blue dots) [27,52,53]. The $\Delta \Psi_{\mathrm{m}}$ across the inner mitochondrial membrane drives the carboxylate head group through an electrostatic path composed of basic residues both inside and outside the UCP cavity [70], resulting in a transport of FA to the other side of the membrane. The FA anion diffuses laterally away from UCP, where it is protonated. Protonated FA diffuses rapidly back across the membrane to deliver protons electroneutrally to the matrix by a spontaneous flip-flop mechanism [67], completing the cycle.

B) Fatty acid shuttling-carrier mechanism considers UCP1 protein as a "carrier" where FA shuttles back and forth across the inner mitochondrial bound to UCP1 (wobbling) [48]. This mechanism differs from the fatty acid cycling mechanism in that the FA molecule cannot diffuse away from the UCP protein and stays bound to the protein, in an unspecified way, while being exposed to the cis or trans side of the membrane either as anion or after protonation. In this case, both anionic and neutral protonated FA are carried through the UCP1 protein. However, the mechanism seems unlikely since the actual fatty acid binding site has been verified to face the lipid bilayer [27,52,53].

plausible hypothesis that FA cycling proceeds predominantly within the specific portion of the IMM forming the rich enfolded cristae, the intracristal space (ICS) membrane [55].

The FA cycling mechanism assumes that UCP1 and other UCPs are not protonophores but fatty acid anion uniporters (Fig. 1) $[39,46,50,51]$. The anionic $\mathrm{FA}^{-}$is translocated by UCP from the matrix surface of the ICS membrane toward its ICS surface, thus consuming the established $\Delta \mathrm{p}$. After the UCP-mediated translocation, the anionic $\mathrm{FA}^{-}$ 
is protonated. At physiological $\mathrm{pH}$, the protonated, neutral $\mathrm{FA}$, can easily flip back across the lipid bilayer of ICS membrane to its matrix surface. As a result, uncoupling and concomitant $\Delta \mathrm{p}$ consumption is not taking place within the UCP protein, but is facilitated by spontaneous diffusion of protonated FAs across the phospholipid membrane (flipflop mechanism). The continuation of the cycle is ensured by FA ${ }^{-}$anion transport, which is mediated by UCP. The overall FA cycling thus leads to apparent UCP-mediated $\mathrm{H}^{+}$translocation [46,56-58].

Crucial support for the FA cycling hypothesis comes from the observations of the inability of so-called "inactive FAs" (such as long chain dicarboxylic acids, FAs with bulky or polar groups at the $\omega$ end) to induce the protonophoric ability of UCP1 $[56,59]$. In contrast to the fatty acid cycling model, the protonophoric model postulates that the role of fatty acids is to insert into UCPs providing their $\alpha$-carboxyls for proton conductance through UCPs [34,44]. If the protonophoric model is correct then bulky or polar groups at the $\omega$ end of long chain fatty acids should not affect function. Since these FAs are also unable to flipflop across the lipid bilayer in a protonated form, the observation of the absence of UCP1 activation with "inactive FAs" strongly supports FA cycling hypothesis. An apparent exception to the "inactive FAs" came in the form of perfluro-octanesulfonate which was reported to activate UCP1 protonophoric function [60], contrary to a wide array of alkylsulfonates which do not activate [46,52,61]. However, a disturbance of the lipid bilayer by perfluro-octanesulfonate is thought to account for the nature of this exception [62].

Interestingly, Echtay et al. [63] looked at the fatty-acid-dependent $\mathrm{H}^{+}$transport activity in Escherichia coli expressed UCP1 reconstituted into liposomes and determined that coenzyme Q (CoQ) was an obligatory cofactor for UCP1 function. They also found that the $\mathrm{H}^{+}$ transport was highly sensitive to purine nucleotides in this reconstituted system, and activated only by oxidized CoQ (ubiquinone) but not reduced $\mathrm{CoQH}_{2}$ (ubiquinol). Moreover, they established that $\mathrm{H}^{+}$ transport of native UCP1 correlated with the endogenous CoQ content [63]. This result was challenged by Jaburrek and Garlid [41], who found that reconstituted recombinant UCP1 is unaffected by oxidized CoQ and concluded that CoQ is not a cofactor of UCP-mediated proton transport [41]. This controversy raised the question of the many challenges associated with the isolation and refolding of bacterially expressed membrane proteins. Specifically, it led to speculation that the need for CoQ might have reflected specific experimental conditions used in Echtay et al. [63] and that the addition of CoQ (and/or the associated solvent) might have promoted structural changes that enabled misfolded UCP1 to support FA-dependent $\mathrm{H}^{+}$transport [41].

In support of the lack of the effect of CoQ on UCP1 activity, it was found that oxidized CoQ was not required for proton conductance by UCP1 heterologously expressed in yeast mitochondria [64]. In this study, Saccharomyces cerevisiae mutant strains lacking CoQ and expressing UCP1 were used to determine whether CoQ was required for UCP1 function. Because the activity of UCP1 was similar in both CoQcontaining and CoQ-deficient yeast mitochondria, the authors concluded that CoQ is neither an obligatory cofactor nor an activator of proton transport by UCP1 when it is expressed in yeast mitochondria [64]. Further detailed studies on the effect of CoQ using heterologously expressed rat UCP1 in yeast mitochondria, as well as native UCP1 in rat BAT, indicated that the endogenous ubiquinone redox state had no effect on fatty acid-induced UCP1 activity in the absence of GTP, and can only regulate this activity through sensitivity to inhibition by the purine nucleotide [65]. Namely, the CoQ redox state-dependent alleviation of UCP1 inhibition by the purine nucleotide was observed at a high CoQ reduction level (exceeding $85 \%$ of total CoQ). Even though these findings indicate that UCP1 sensitivity to GTP can be regulated by the redox state of membranous CoQ, they provide no mechanism, explaining how ubiquinol could directly interact with UCP1. Instead, the correlation between the mitochondrial redox state, CoQ redox state and the ability of purine nucleotides to inhibit FA-dependent $\mathrm{H}^{+}$transport by UCP1 may be attributed to the direct oxidative post-translational modification of UCP1, such UCP1 Cys253 sulfenylation, as demonstrated by Chouchani et al. [66].

An alternative model to the fatty acid cycling model was recently hypothesised for UCP1 function. It was proposed that both $\mathrm{FA}^{-}$anions and neutral protonated FAs are transported by UCP1 and that neither FA form diffuses out of the protein during this mechanism [48]. This FA shuttling mechanism is however unlikely from a thermodynamics point of view [55] and is incompatible with the revealed structures of UCPs, specifically with the existence of the surface FA binding site. In this model, FAs does not diffuse out of UCP to the phospholipid bilayer, but remains bound to the UCP by hydrophobic interactions. Protonated FAs thus carry (shuttles) $\mathrm{H}^{+}$back to the matrix while still attached to the protein. However, the hydrophobic interaction does not allow FAs to reach thermodynamic equilibrium between UCP and the phospholipid bilayer. Given the extremely fast rate of protonated FAs movement across the phospholipid bilayers [67] and the relatively slow transport of ionized FAs by UCPs $[40,46]$, the proposed hydrophobic interaction of FAs with the UCP would have to be orders of magnitude stronger than the hydrophobic interaction of FAs with the membrane, a key fact that undermines this model. Furthermore, the known dependence of UCP activity on specific fatty acid chain length $[42,68]$ is also inconsistent with the FA shuttling mechanism [48] and, more consistent with the FA cycling hypothesis.

Other models, pronouncing the net protonophoric function of UCP1, are still debated [69], despite the experimental evidence to the contrary, from studies on UCP2 structure and FA interaction with UCP2 [55]. Furthermore, the interaction of UCP1 with FAs have been studied using NMR [53]. The authors clearly demonstrated that FA directly binds UCP1 at the interface between transmembrane $\alpha$-helix $\mathrm{H} 1$ and H6. The paramagnetic relaxation enhancement together with molecular dynamics simulation, demonstrated that the FA carboxylate group is attracted by basic residues on UCP1 near the matrix side, whereas the hydrophobic FA tail fits into the H1/H6 groove. The FA binding is thus similar to the FA binding to UCP2 described previously [52,70]. Also, mutagenesis experiments carried out on UCP2 and UCP1 yield similar outcomes [52] - decreased UCP-mediated $\mathrm{H}^{+}$flux at substitutions on FA interacting residues. In conclusion, structure/functional relationships support the identical uncoupling mechanism by UCP1 and UCP2 and support the FA cycling mechanism.

\subsection{Nascent fatty acid requirement for uncoupling protein function and synergy with mitochondrial phospholipases}

Recently, another detail was revealed for UCP1 functional activation in vivo, based on the observation that only those fatty acids instantly cleaved by mitochondrial phospholipases induce UCP1-mediated uncoupling [48]. This phenomenon was indicated during studies by direct patch-clamp of UCP1 within its natural IMM environment of BAT mitochondria [48]. A similar phenomenon has been described for UCP2 in INS-1E cells with involvement of redox-activated iPLA2 $\gamma$ in synergy with UCP2, acting as an antioxidant mechanism and redox suppressing regulator [71]. Studies using mitochondria isolated from tissues rich in UCP2 [72] also identified $\mathrm{H}_{2} \mathrm{O}_{2}$-activated mitochondrial iPLA2 $\gamma$ as the main regulator of the UCP2 activity. Typically, iPLA2 $\gamma$ is activated by $\mathrm{H}_{2} \mathrm{O}_{2}$ formed from superoxide during $\mathrm{FA} \beta$-oxidation. Thus, iPLA2 $\gamma$, by cleaving phospholipids and releasing free FAs, provides the anionic substrates for UCP2-mediated uncoupling. The consequent partial dissipation of $\Delta \mathrm{p}$ initiates a direct feedback attenuation of mitochondrial superoxide production [71-73]. It remains to be established whether during typical FA $\beta$-oxidation, which is a hallmark of BAT thermogenesis, iPLA2 $\gamma$ also cleaves free FAs for UCP1, and whether this mechanism supersedes the "classic" mechanism where FAs from lipolysis (not yet esterified to FA-CoA and FA-carnitine for the carnitine cycle) are cycling substrates of UCP1. Speculatively, iPLA2 $\gamma$ might be activated by the same redox signal that leads to sulfenylation of Cys253 on UCP1 [66], as we will discuss later. Our preliminary data 
from experiments comparing iPLA2 $\gamma$ KO mice to wild-type mice support the partial contribution of the redox-activated iPLA2 $\gamma$ to the initiation of BAT thermogenesis (Jabůrek et al., unpublished).

\subsection{Implications for UCP1 function and regulation based on UCP1 structure}

Early studies by Martin Klingenberg had concluded that UCP1 $(\sim 32 \mathrm{kDa}$ as a monomer) exists within the IMM as a dimer which is able to bind just a single molecule of nucleotide [74]. Recently, it has been shown that the monomeric UCP1 can exists which binds a single nucleotide [75]. These detergent-free purified UCP1 preparations retained the tightly bound three molecules of cardiolipin per monomeric UCP1. The structure of UCP1 is implicitly modeled as based on the crystal structure of the ADP/ATP carrier [76], since the common structural features exist for the whole mitochondrial anion carrier protein, i.e. SLC25, gene family [77]. Alternatively, UCP1 could be modeled analogously to the NMR structure of UCP2 [52,70]. In both cases, critical conserved positively charged residues exist on the protein surface that were demonstrated to bind fatty acids as well as containing an ICS facing binding site (cytosolic orientation) for purine nucleotide binding. In addition, valuable information was attained by Zhu et al. [27] who mapped the nucleotide binding site of UCP1 using atomic force microscopy. By comparing recognition patterns obtained with an antiUCP1 antibody and the ligand ATP they demonstrated that the ATP binding site can be accessed from both sides of the membrane. However, only binding from cytosolic side leads to the protein conformational changes and inhibition of UCP1. They also calculated that the distance of the binding site from the surface is approximately $1.27 \mathrm{~nm}$, thus providing further valuable structural information about UCP1.

\subsection{Posttranslational modifications of UCP1}

Detailed identification of post-translational modification of proteins is now available with the advent of advanced mass spectroscopy. Enormous physiological significance has been associated with sulfenylation, acetylation, succinylation and other residue modifications. For example, acetylation of numerous mitochondrial proteins inhibits their function, whereas their deacetylaton, by certain sirtuins, promotes metabolism and oxidative phosphorylation. Among mitochondrial sirtuins, sirtuin 3 is a $\mathrm{NAD}^{+}$-dependent deacetylase essential for oxidative phosphorylation [78], whereas sirtuin 5 does a similar job while acting as a potent desuccinylase [79]. Among mitochondrial proteins targeted are subunits of the ATP synthase, optic atrophy associated protein 1 (OPA1), and magnesium dependent superoxide dismutase (MnSOD) which are inhibited by acetylation and physiologically activated by sirtuin 3. Similarly enzymes of fatty acid $\beta$-oxidation and ketogenesis are activated by sirtuin 5 mediated de-succinylation [80] and, interestingly, sirtuin 4 removes three acyl moieties from lysine residues on enzymes associated with leucine metabolism [81]. Nevertheless, it has to be determined, whether UCPs also possess modified lysine residues.

Sulfenylation of cysteines is another type of posttranslational modification, reported to be employed in transmittance of the redox signalling by thioredoxins, peroxiredoxins or glutaredoxins [82]. Recently, this type of modification has been proposed to be essential for initiation of thermogenesis in BAT. Specifically, Cys253 of UCP1 has been identified as the key regulator of non-shivering thermogenesis, being oxidized to a sulfenyl by reactive oxygen species (ROS) upon norepinephrine stimulation of BAT or brown adipocytes [66]. Criticism of the finding focuses on the mechanistic link between norepinephrine stimulation and the redox changes required to provide sulfenylation [55]. In addition, there would have to be quite a strong redox signal to modify the significant amount of UCP1 present in BAT, therefore one might also expect analogous cysteines of the other carriers of the SLC25 family to be modified, which they are not [69]. Consequently, further research on the signalling pathways involved and the relevance in vivo requires further investigation.

An intriguing speculation on our part, alluded to earlier, that could unify known aspects of UCP1 activation, is the redox dependent activation mechanism which has been proposed for UCP2 [71]. In essence, nascent FAs are cleaved from cardiolipin and phospholipids in the IMM by the redox activated phospholipase iPLA2 $\gamma$ (PNPLA8). The phospholipase provides the substrate for UCP flipping activity, while the long chain fatty acyl carnitines, brought to the matrix for $\beta$-oxidation as a result of norepinephrine/PKA- stimulated BAT lipases in the cytosol, provide the substrate for a sufficient ROS burst by ETF:QOR to which other respiratory chain or $\alpha$-glycerol- phosphate dehydrogenase may also contribute. However, it is important to note that the functional activation of iPLA2 $\gamma$ during norepinephrine stimulation of brown adipocytes has yet to be demonstrated.

\subsection{Fatty acid cycling and thermogenesis}

How compatible is the fatty acid cycling model with mitochondrial heat production? What is the advantage of the fatty acid cycling model over a simple protonophoric channel (uniport) mechanism when it comes to explaining heat production? One can search for a clue in the mitochondrial ultrastructure of enfolded cristae [83], which are very prevalent in BAT mitochondria. Recent evidence suggests that proton pumps are concentrated within the supercomplexes and are localized in the flatter cristae walls [84]. These supercomplexes pump protons, not to the cytosol per se but, to mostly prolongated intracristal spaces (ICS), oriented perpendicularly toward the cylindrical structure that is made up of the outer mitochondrial membrane (OMM), the (outer) intermembrane space region and the inner boundary membrane (IBM) (Fig. 2). The IBM thus represents an inner side of a cylinder of unfolded IMM, not part of the crista outlets emanating from the IBM and from where junction proteins form joints with the OMM. These cylindrical morphologies form the tubules of the mitochondrial network, which are connected in many tissues, including skeletal muscle and heart. The mitochondrial network undergoes fission and fusion and remains connected when these two processes are balanced or fusion prevails. The membrane network in brown adipocytes has been frequently studied $[85,86]$.

Coupling between the proton pumps and ATP synthesis is, therefore, localized to the ICS and involves two-dimensional (2D) diffusion of $\mathrm{H}^{+}$ from the flat cristae walls to the cristae edges, where dimers of the ATPsynthase are localized (Fig. 2). Any uncoupling must interrupt this 2D diffusion, otherwise local coupling is intact. The advantage of the FA cycling model over protonophoric channels lies in the fact that in order to be efficient, any presumably proteinaceous channel would have to be very abundant, so as to be able to intersect all paths of $2 \mathrm{D}$ diffusion. Such hypothetical $\mathrm{H}^{+}$channels should be preferentially located also in the flat cristae walls to scavenge $\mathrm{H}^{+}$closest to their outlet sites of supercomplex proton pumps (Fig. 2B). In contrast, the anionic $\mathrm{FA}^{-}$is able to diffuse in the 2D plane of the ICS-adjacent lipid leaflets of the ICS membrane (a folded portion of IMM), the fatty acids can easily reach the cardiolipin annuli around the protein complexes and after $\mathrm{FA}^{-}$ protonation, i.e. after scavenging the pumped $\mathrm{H}^{+}$, the neutral FA can flip-flop back to the matrix-adjacent lipid leaflets of ICS membrane. 2D diffusion in the plane of the membrane ensures fast access to the UCP (Fig. 2A). Anywhere on its route within the matrix ICS membrane, surface neutral FAs can be deprotonated which is facilitated by the more alkaline matrix $\mathrm{pH}$. UCP is not localized in the proximity of the ATP synthase, hence fast turnover of uncoupling is ensured by the involvement of numerous FA and probably also by constant FA cleavage from mitochondrial membranes by phospholipase iPLA2 $\gamma$. Recently Pohl's group have shown that UCP4 is spatially separated from the ATP synthase in neuronal mitochondria [87]. UCP4 is also regarded as a proton transporter activated by fatty acids [88]. The localization of UCP4 at the inner boundary membrane (IBM) is consistent with the view that it dissipates the excessive proton gradient, without affecting 


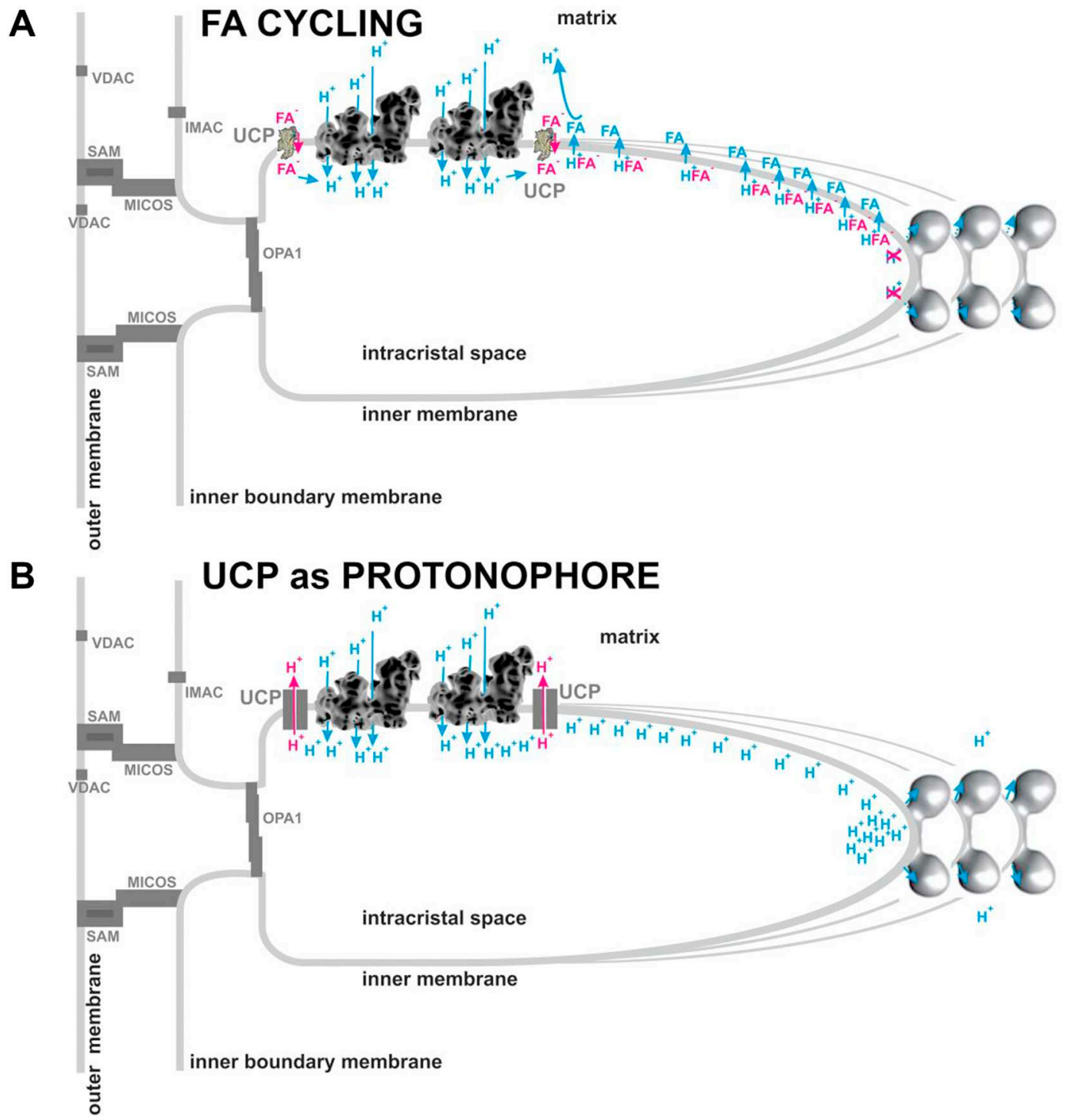

Fig. 2. Advantage of FA cycling for uncoupling of inner mitochondrial membrane cristae at existing 2D proton diffusion.

Coupling between the proton pumps of the respiratory chain supercomplexes (depicted as dark grey clusters in the inner membrane), located at flat cristae regions, and ATP synthase dimers (depicted as light grey bulbus protrusions from the right edge of the inner membrane edge), organized in arrays at the cristae edges, must involve 2D diffusion of $\mathrm{H}^{+}$from the flat cristae walls to the cristae edges. The advantage of the (A) FA cycling mechanism over (B) the protonophoric channel mechanism of uncoupling lies in the following:

A) Anionic FAs diffuse in the 2D plane of the membrane to reach the cardiolipin annuli around the supercomplexes, where they are protonated by incoming $\mathrm{H}^{+}$from $\mathrm{H}^{+}$pumping. The resulting neutral FAs flips back to the matrix-adjacent lipid leaflets and their 2D diffusion within the membrane ensures their fast translocation to UCP. Essentially, anywhere on their route neutral FAs can be deprotonated, facilitated by the more alkaline matrix pH. Since UCP is not localized in proximity to the ATP synthase dimer, a fast turnover rate of uncoupling is ensured by numerous FA molecules being involved.

B) In contrast, in order to achieve a fast turnover rate of uncoupling, any proton translocating proteinaceous channel would have to be very abundant, so as to be able to intersect along the path of $2 \mathrm{D}$ diffusion. Such $\mathrm{H}^{+}$channels should also be preferentially located in the inner membrane flat cristae walls to scavenge $\mathrm{H}^{+}$closest to their outlet sites of supercomplex proton pumps.

Abbreviations: IMAC - inner membrane anion channel; MICOS - mitochondrial contact site and cristae organizing system; OPA1 - Optic atropy type 1 protein; SAM sorting and assembly machinery; UCP - uncoupling protein; VDAC - voltage-dependent anion channel.

ATP production. The competition between UCP1 and the ATP synthase was not convincingly shown in BAT, so the possibility exists that UCP1 is also localized at IBM.

\section{Brown adipocytes as an ideal environment for promoting thermogenesis}

\subsection{Norepinephrine stimulation of BAT}

Brown adipose tissue (BAT) is formed predominantly by brown adipocytes containing multiple small lipid droplets and high content of mitochondria and it is highly vascularized and innervated so that nearly each cell has its own nerve terminal [11]. BAT tissue also contains preadipocytes with the ability to differentiate into brown adipocytes $[89,90]$. In rodents small BAT depots are distributed in interscapular, subscapular, axillary, perirenal and periaortic regions. The sympathetic nervous system centrally regulates nonshivering thermogenesis stimulated by norepinephrine via $\beta 3$ - adrenergic receptors in rodents but predominantly by $\beta 1$ - adrenergic receptors in humans [12]. It has long been established that the cold-induced sympathetic stimulation of brown adipocytes activates lipolysis, glucose uptake, as well as mitochondrial biogenesis. This acute norepinephrine stimulation of BAT 


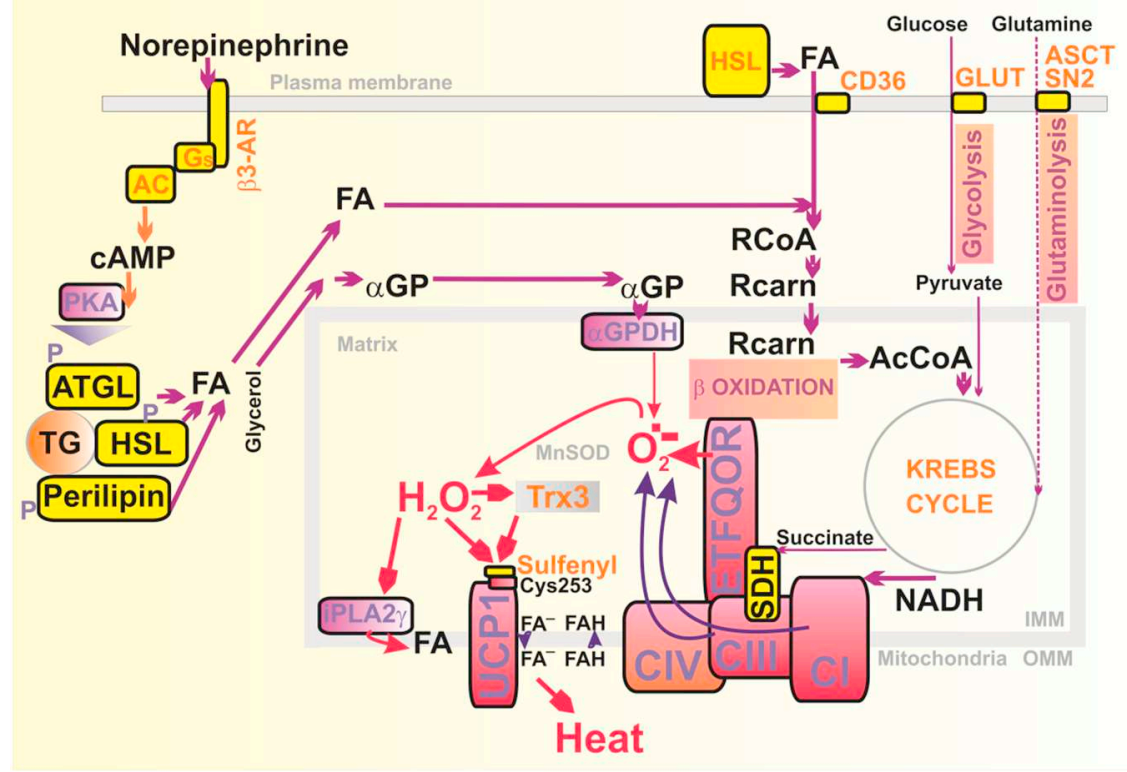

Fig. 3. Nonepinephrine initiation of thermogenesis in brown adipocyte.

The scheme describes the known cascade of events beginning with adrenergic receptor stimulation with norepinephrine and combines this with a predicted hypothetical participation of the redox-activated mitochondrial phospholipase iPLA2 $\gamma$ providing nascent fatty acids for UCP1-mediated uncoupling, thus substantiating heat production. Also, depicted is the possible is the participation of thioredoxin TRX3 in the transfer of redox signal resulting in sulfenylation of critical cysteine 253 for activation.

Abbreviations: $\beta 3$-AR - $\beta 3$ - adrenergic receptor; AC adenylated cyclase; ASCT - glutamine transporter; ATGL - adipose triglyceride lipase; $\alpha \mathrm{GP}-\alpha$-glycerolphosphate; $\alpha \mathrm{GPDH}$ - $\alpha$-glycerolphosphate dehydrogenase; CD36 - fatty acid transporter; CI, CII, CIV- respiratory chain complexes; ETFQOR - electron transfer flavoprotein: uniquinone oxidoreductase; FA - fatty acid; GLUT - glucose transporter; HSL - hormone-sensitive lipase; RCoA acylCoA; iPLA2 $\gamma$ - calcium-independent phospholipase A2 $\gamma$; MnSOD - manganese superoxide dismutase; PKA - protein kinase A; RCarn - acylcarnitine; SDH - succinate dehydrogenase; SN2 glutamine transporter; TG - triglyceride. leads to heat generation and the essential thermogenic role of UCP1 for nonshivering thermogenesis in rodents has been confirmed by comparison with UCP1 knockout mice [91-94] (Fig. 3).

The norepinephrine stimulation cascade, controlling both acute thermogenesis and BAT recruitment, involves at its first step a coupling of the $\beta$-adrenergic receptor with a Gs protein which activates adenylyl cyclase leading to formation of a second messenger cAMP [95,96]. Subsequently, cAMP promotes PKA-mediated phosphorylation of cytosolic lipolytic enzymes and other proteins including nuclear proteins. The main acute response thus includes lipolysis of lipid droplets by activation of hormone-sensitive lipase (HSL), adipose triglyceride lipase (ATGL), and perilipin. Lipolysis produces free FAs, which as UCP1 cycling substrates, mediate mitochondrial uncoupling and heat production. FAs are imported into the matrix by the so-called carnitine cycle whereby acyl-CoA's are condensed to acyl-carnitine esters by carnitine palmitoyltransferase 1 (CPT1). The mitochondrial carnitine carrier then imports long chain acyl-carnitine esters to the matrix in exchange for short-chain acylcarnitines or L-carnitine. Acyl carnitines are converted back to acylCoA by CPT2 and acylCoA's are substrates for $\beta$-oxidation in the matrix, producing superoxide by ETF:QOR protein feeding electrons via FAD to the respiratory chain. In the non-activated resting state, FAs in BAT are recruited into the lipid droplets by lipoprotein lipase and the FA transporter CD36, the ablation of which impairs BAT function [89]. Interestingly, a glucagon peptide-1 (GLP-1) analog is also known to activate BAT in mice [97].

The chronic effects involving UCP1 stem mostly from the transcriptional regulation of UCP1 expression [98]. A distal enhancer and proximal promoter have been recognized to act in UCP1 transcriptional regulation. Both are involved in the PKA-mediated upregulation of UCP1 expression, directly via the cAMP-responsive element binding protein (CREB) recruited to the proximal promoter, where also the PRD1-BF-1-RIZ1 homologous domain-containing protein-16 (PRDM16) binds to flanking regions [99], either with CCAAT-enhancer binding proteins $\alpha$ and $\beta$, or with lysine-specific demethylase and zinc finger protein 516. Alternatively, PKA via p38 mitogen-activated protein kinase (p38 MAPK) activates the activating transcription factor 2 (ATF2) in the distal enhancer. The ATF2 region is preceeded by three retinoid receptor (RXR) sites, all stimulated by peroxisome proliferator-activated receptor $\gamma$ coactivator $1 \alpha(\mathrm{PGC1} \alpha)$ [100]. The middle site can be activated by fibrates and thiazolidinediones via peroxisome proliferator-activated receptor $\alpha$ or $\gamma$ (PPAR $\alpha$ or $\gamma$ ), which also requires binding of PRDM16, PGC1 $\alpha$, receptor-interacting protein 140 and liver $\mathrm{X}$ receptor [98]. Thyroid hormones manifest their effect via the most distal site upon complex formation of the thyroid receptor with RXR and PGC1 $\alpha$.

Thus the main chronic effects of adrenergic stimulation are driven by PKA-mediated phosphorylation of nuclear proteins, which leads to BAT growth by hyperplasia and hypertrophy, increased mitochondrial biogenesis via p38 MAPK signalling and elevating PGC1 $\alpha$ expression. Simultaneously BAT angiogenesis stems from participation of VEGF. Note also that BAT biogenesis is stimulated via the JAK/STAT pathway [101] and by Sirtuin 1 (SIRT1) [102]. Interestingly, without "alarmin", i.e. the IL33 nuclear cytokine activating type 2 immune response, brown adipocytes develop without appropriately spliced ucp 1 mRNA and hence do not express UCP1 protein [103].

\subsection{Brite/beige adipose tissue}

Besides the existence of BAT, there also exists brown in white (brite) tissue (also termed beige) at certain loci within WAT [104,105]. Despite containing UCP1, beige adipocytes come from a different developmental lineage to brown adipocytes. Beige adipocytes develop from capillary networks in response to pro-angiogenic factors and consequently should probably be considered a different cell type [106]. The myf5 ${ }^{+}$lineage (myogenic factor 5 , myf5-dependent), which is also common for skeletal muscle, is determining in brown adipocytes, whereas a myf5 ${ }^{-}$lineage is the precursor for beige adipocytes [99]. In the basal state, beige adipocyte exhibit low UCP1 expression, which is significantly enhanced upon hormonal stimuli linked to cAMP [104]. Therefore, some BAT depots, in humans considered previously as composed of brown adipocytes, might be depots of beige adipocytes.

An intriguing idea supported by the recent advances in BAT research assumes that in obesity, inflammation of WAT results in decreased biogenesis brite/beige adipocytes, which otherwise contribute to elevated energy expenditure within WAT, because of their functional thermogenic UCP1 [13]. The ability of overexpressed UCP1 in pig WAT (pigs don't have UCP1) to decrease fat depositions and enhancing thermogenic capacity has been suggested as proof of the concept [107]. The molecular mechanisms involved in this etiology type of obesity development are widely studied. The inhibitory mechanism for beige adipogenesis involves direct adhesion of macrophages to adipocyte integrin $\alpha 4$ resulting in ERK-dependent downregulation of UCP1 
expression [108]. The involvement of paracrine secretion in these macrophage-WAT interactions downregulating oxidative phosphorylation related respiration in humans was also indicated [109]. Also inhibition of signalling by the Gq family of G-protein coupled receptors (GPRC) enhances differentiation of human and murine brown adipocytes [110]. The endothelin/Ednra pathway was identified as an autocrine activator of Gq signalling in BAT. Gq expression in human WAT inversely correlated with UCP1 expression, consequently Gq signalling is thought to negatively regulate brown/beige adipocyte biogenesis.

Recent advances in UCP1 expression include the discovery of the aforementioned alarmin/IL-33, an essential factor, the absence of which results in beige and brown adipocytes not expressing an appropriately spliced ucp1 mRNA [103]. Beige adipocytes exhibit inducible UCP1 expression in response to cold exposure [111,112]. Their adipogenesis stems, on the one hand from committed progenitor cells and on the other hand, from the transdifferentiation of white adipocytes. The latter process is believed to be stimulated by type 2 cytokine signalling of macrophages [113].

Despite all the aforementioned, two types of beige adipocytes have been proclaimed to found, those that express UCP1 and those that do not express UCP1 [114]. Both types have been implicated with another mechanism of molecular heat production base on the creatine dissipative cycle. In the UCP1 positive beige adipocytes the UCP1-related heat production provided the additional heat source. Interestingly, UCP1 was detected in neurons of thirteen-lined ground squirrels, the proposed role there being brain thermogenesis during hibernation [115].

\subsection{BAT in humans}

Existence of BAT in newborn humans has long been known $[116,117]$. Functional BAT has been recognized also in adult humans in cervical, supraclavicular, paravertebral, mediastinal, and perirenal regions [118-121]. Interestingly, the haplotypes covering the ucp1 region correlating with higher non-shivering thermogenesis score also correlated with more northern latitude, showing that during evolution UCP1 gene was related to cold adaptation [122].

PET studies using ${ }^{18} \mathrm{~F}$-fluoro-deoxyglucose (FDG) have confirmed the existence of functional BAT in adult humans. Adults retain a minor amount of BAT past infancy (30 to $85 \mathrm{~g}$ in "high BAT subjects contrasting to $<2 \mathrm{~g}$ BAT for low BAT" subjects) but that BAT contributes only a small amount to cold-induced thermogenesis [123]. That amount was quantified recently using determinations of human BAT oxygen consumption by $\left[{ }^{15} \mathrm{O}_{\mathrm{O}_{2}}\right.$ PET imaging during cold exposure of human subjects. The results indicated that BAT contributed only $\sim 1 \%$ of total body elevation in energy expenditure [124]. Interestingly mitochondria of permeabilized human BAT, obtained by a PET-CT guided biopsy, showed a 50-fold respiratory capacity versus human WAT, with a significant proportion of that oxygen consumption being inhibitable by GDP in BAT [125]. BAT in humans is activated under the same conditions as in rodents and under systemic impairment of lipid metabolism [126]. It has been reported that such activation improves glucose homeostasis and insulin sensitivity in humans [127].

Brite/beige adipogenesis has also been identified in humans, e.g. under adrenergic stress [128]. The exposure of human subjects to the cold promotes secretion of FGF21 and the myokine, irisin, both of which stimulate formation of beige adipocytes [129]. Other players in brown fat activation and WAT browning include MP10, an inhibitor of phosphodiesterase 10A which stimulates BAT biogenesis, and "browning" of WAT [130] and MKK6, an activator of p38 MAPK, ablation of which increases UCP1 expression in adipocytes and T3-dependent browning of white adipocytes [131].

\section{Thermogenic function only within the promoting environment}

\subsection{Heat promoting aspects in $B A T$}

In terms of heat production, microcalometric studies indicate that BAT in cold-acclimated rats has five times the power (mW) of BAT in non-cold acclimated animals [28]. The heat released from palmitoylcarnitine oxidation by BAT mitochondria clearly shows a reciprocal relationship between $\Delta \mathrm{p}$ and heat release [29]. Furthermore, intact isolated brown adipocytes were demonstrated to produce heat when stimulated with norepinephrine [28]. Likewise significant temperature increases (by $1{ }^{\circ} \mathrm{C}$ ) have been reported in the media of a liquid culture calorimeter when yeast strains expressing endogenously active UCP1 mutants were grown [132]. Moreover, temperatures of up to $50^{\circ} \mathrm{C}$ has been reported in HEK cells expressing UCP1 [133]. Nevertheless the significance of the fraction by which UCP1-mediated heat release contributes to whole body non-shivering thermogenesis has been debated over the decades and, as mentioned above, the fraction of heat release specifically in adult humans, is rather low.

\subsection{Switching between mild and thermogenic uncoupling}

In intact brown adipocytes UCP1 is constantly inhibited by purine nucleotides (ATP, ADP, GTP or GDP) penetrating into the mitochondrial ICS from the cytosol. The purine nucleotide inhibition is overcome upon norepinephrine stimulation. The mechanism by which purine nucleotide inhibition of UCP1 occurs is not yet fully elucidated. However, it is plausible that conformational changes induced by fatty acids are involved. For example, the binding of GDP to UCP2 induces conformational changes affecting Gly281 and Gly19 [52]. Pioneering electron spin resonance (EPR) studies indicated that 5-doxyl-C18 FA interactions with UCP1 were affected by GDP-induced conformational changes $[26,134]$. The "open" and "closed" state of UCP1 has been simulated using isolated BAT mitochondria under physiological $\mathrm{Mg}^{2+}$ conditions and using physiological ATP, ADP and AMP concentrations found in nonepinephrine-stimulated and resting state BAT, respectively [25]. Since it has long been known that alkaline $\mathrm{pH}$ decreases purine nucleotide inhibition of UCP1 $[24,135,136]$, one might predict a physiological role for the local ICS pH becoming more alkaline upon uncoupling, however indications are that in uncoupled mitochondria ICS $\mathrm{pH}$ is rather acidic especially at cristae edges containing ATP-synthase dimers [83].

It has long been postulated that mild uncoupling, a partial dissipation of $\Delta \mathrm{p}$, is involved in regulating mitochondrial superoxide formation [1]. However, switching between mild and thermogenic uncoupling does not consist only of switching on UCP1 while insuring its persistent expression (one also sees suppression of ATP-synthase expression in BAT), but thermogenic uncoupling requires a continuous supply of respiratory chain substrates. For instance, uncoupled respiration requires $\beta$-oxidation of FAs not only provided by norepinephrine-stimulated lipolysis of lipid droplets (and $\alpha$-glycerol phosphate from those sources), but also fatty acids from lipoproteins developed as physiological means of prolongated non-shivering thermogenesis [11].

Resting brown adipocytes, i.e. non-thermogenic brown adipocytes are also interesting metabolically. For example, brown adipocyte cell lines exhibit reductive carboxylation, i.e. isocitrate dehydrogenase 2 (IDH2)-mediated counter Krebs cycle directed substrate flux [137]. In this case, glutaminolysis provides 2-oxoglutarate which is channelled at the expense of NADPH into isocitrate, and via cis-aconitate to citrate, which is exported from the matrix to the cytosol for lipogenesis. It is not known how active this reductive carboxylation is upon norepinephrine stimulation. 


\subsection{UCP1 function in the absence of an environment promoting thermogenesis}

A non-thermogenic but antioxidant function for UCP1 has been found in a diverse group of mammals [138]. Due to the uncoupling nature of UCP1, one might expect lowered ROS production in mitochondria containing active UCP1. There is certainly evidence from isolated mitochondrial studies that UCP 1 can reduce ROS production by BAT mitochondria [126,127] and thymus mitochondria [139], using a variety of mitochondrial substrates. However, others suggest that any role UCP1 may have in regulating ROS production in BAT mitochondria may not be a general rule for all substrates [140]. However, there is evidence emerging, discussed in the next section, of a role for ROS in regulating UCP1 activity.

\subsection{Redox regulation of UCP1 function}

Physiologically triggered covalent modification of UCP1 may not seem too radical an idea, but it is only in recent years that covalent modifications of UCP1 have been detected. The proportion of UCP1 that is phosphorylated (Ser 51) is certainly increased following cold acclimation, yet the role of this covalent modification is unclear [141]. It has also been demonstrated that UCP1 turnover in both BAT and thymus mitochondria requires the proteasome- ubiquitinylation system [142]. Recently, it was revealed that postranslational modifications can provide a switch that initiates nonshivering thermogenesis in BAT $[36,66]$. All three species of ROS, namely mitochondrial superoxide, hydrogen peroxide, as well as lipid hydroperoxides, were indicated in this mechanism upon cold exposure of mice. Mitochondrial targeted antioxidant MitoQ prevented these changes, which were also absent in $\mathrm{UCP} 1^{-/-}$mice. MitoQ also induced hypothermia upon cold exposure but did not affect muscle shivering which would be considered an early thermogenic response to cold. It was also demonstrated that upon cold exposure, the BAT glutathione pool was extensively reduced and BAT protein thiols, including sulfenyls, were extensively oxidized. An instant rise in superoxide was also observed in isolated brown adipocytes upon norepinephrine stimulation, typically associated with increased (uncoupled) respiration. It transpires that Cys253 of UCP1 is sulfenylated under noradrenaline stimulation. Interestingly, Cys253 is conserved in UCP2, UCP3, and faces the matrix side on structural models of UCP1, based on the crystal structure of the ADP/ATP carrier structure. Replacement by Cys 253 with Ala (as well as replacement of Cys224) resulted in blockage of norepinephrine-induced respiratory rise, i.e. uncoupling and increased sensitivity to GDP inhibition. It should also be noted that in the case of the Cys253Ala UCP1 mutant (but not for Cys224Ala), norepinephrine, at higher doses, overcame the aforementioned insufficiency.

\subsection{When a rise of mitochondrial ROS sources overwhelms their attenuation by uncoupling}

Uncoupling even in its mildest form (a few $\mathrm{mV}$ reduction in $\Delta \mathrm{p}$ ) possesses the ability to attenuate superoxide formation originating from certain mitochondrial sources (those dependent on $\Delta \mathrm{p}$ ), specifically from Complex I and Complex III Q sites (for detailed review see [55,83,143-145]. Evidence has also been presented of direct activation of UCP1 by certain ROS generated products such as 4-hydroxy-nonenal (4-HNE) modification, facts that were disputed by later studies [146-148]. Indeed, it has been shown that lipid ethanolamine modifications, by reactive aldehydes such as 4-HNE, can cause increased proton leak [149]. Nevertheless, the hypothesis of a ROS-induced attenuation of superoxide formation has been made plausible by the observation of UCP1 Cys253 sulfenylation. Nevertheless, consequences of this redox UCP1 modification on acute or chronic ROS formation is still an area of robust investigation.

Cold-induced stimulation of BAT when UCP1 is ablated, promotes excessive mitochondrial ROS production that, contrary to the situation in wild-type mice, induces mitochondrial $\mathrm{Ca}^{2+}$ overload and concomitant dysfunction, as indicated by markers of cell death and recruitment of innate immune signalling [150]. The impaired mitochondrial function of UCP1 KO mice exhibited lower amounts of respiratory chain subunits encoded by mtDNA, and decreased gene expression for oxidative phosphorylation [150].

\subsection{Non-canonical roles for UCP1}

Apart from being in BAT and beige/brite adipose tissue, there are layers of convincing evidence that UCP1 is present in thymus [152,153], although there is some evidence to the contrary [151]. The insensitivity of UCP1 expression in thymocytes to cold-adaptation suggests no thermogenic role for UCP1 in thymus [152]. However, an absence of mitochondrial UCP1 affects apoptosis in thymocytes, resulting in reduced peripheral (spleen) T-cell production by up to twothirds, and an overall reduced $(\sim 85 \%)$ in CD8 + T-cells production [153].

\section{Transparency document}

The Transparency document associated with this article can be found, in online version.

\section{Acknowledgements}

The project was supported by grant of the Grant Agency of the Czech Republic No. 17-01813S to P.J.; and the research projects RVO67985823 and LTUSA17174. Additional UCP1 work was supported by project grants to R.K.P. from Science Foundation Ireland.

\section{References}

[1] V.P. Skulachev, Uncoupling: new approaches to an old problem of bioenergetics, Biochim. Biophys. Acta Bioenerg. 1363 (1998) 100-124.

[2] M. Jastroch, A.S. Divakaruni, S. Mookerjee, J.R. Treberg, M.D. Brand, Mitochondrial proton and electron leaks, Essays Biochem. 47 (2010) 53-67.

[3] K.D. Garlid, A.D. Beavis, S.K. Ratkje, On the nature of ion leaks in energy-transducing membranes, BBA-Bioenergetics 976 (1989) 109-120.

[4] C. Pecqueur, M.C. Alves-Guerra, C. Gelly, C. Lévi-Meyrueis, E. Couplan, S. Collins, D. Ricquier, F. Bouillaud, B. Miroux, Uncoupling protein 2, in vivo distribution, induction upon oxidative stress, and evidence for translational regulation, J. Biol. Chem. 276 (2001) 8705-8712.

[5] A. Rupprecht, A.U. Bräuer, A. Smorodchenko, J. Goyn, K.E. Hilse, I.G. Shabalina, C. Infante-Duarte, E.E. Pohl, Quantification of uncoupling protein 2 reveals its main expression in immune cells and selective up-regulation during t-cell proliferation, PLoS One 7 (2012) e41406.

[6] T. Inagaki, J. Sakai, S. Kajimura, Transcriptional and epigenetic control of brown and beige adipose cell fate and function, Nat. Rev. Mol. Cell Biol. 17 (2016) 480-495.

[7] V. Azzu, M. Jastroch, A.S. Divakaruni, M.D. Brand, The regulation and turnover of mitochondrial uncoupling proteins, Biochim. Biophys. Acta Bioenerg. 1797 (2010) 785-791.

[8] F. Shi, S. Collins, Second messenger signaling mechanisms of the brown adipocyte thermogenic program: an integrative perspective, Horm. Mol. Biol. Clin. Invest. 31 (2017).

[9] B.K. Sharma, M. Patil, A. Satyanarayana, Negative regulators of brown adipose tissue (BAT)-mediated thermogenesis, J. Cell. Physiol. 229 (2014) 1901-1907.

[10] G.J. Hausman, R.L. Richardson, Adipose tissue angiogenesis, J. Anim. Sci. 82 (2004) 925-934.

[11] B. Cannon, Brown adipose tissue: function and physiological significance, Physiol. Rev. 84 (2004) 277-359.

[12] J. Nedergaard, B. Cannon, The changed metabolic world with human brown adipose tissue: therapeutic visions, Cell Metab. 11 (2010) 268-272.

[13] M.J. Betz, S. Enerbäck, Targeting thermogenesis in brown fat and muscle to treat obesity and metabolic disease, Nat. Rev. Endocrinol. 14 (2018) 77-87.

[14] P. Trayhurn, Origins and early development of the concept that brown adipose tissue thermogenesis is linked to energy balance and obesity, Biochimie 134 (2017) 62-70.

[15] D. Richard, F. Picard, Brown fat biology and thermogenesis, Front. Biosci. 16 (2011) 1233-1260.

[16] P. Cohen, B.M. Spiegelman, Brown and beige fat: molecular parts of a thermogenic machine, Diabetes 64 (2015) 2346-2351.

[17] V.D. Ramseyer, J.G. Granneman, Adrenergic regulation of cellular plasticity in 
brown, beige/brite and white adipose tissues, Adipocytes 5 (2016) 119-129.

[18] S. Kajimura, B.M. Spiegelman, P. Seale, Brown and beige fat: physiological roles beyond heat generation, Cell Metab. 22 (2015) 546-559.

[19] K. Chechi, A.C. Carpentier, D. Richard, Understanding the brown adipocyte as a contributor to energy homeostasis, Trends Endocrinol. Metab. 24 (2013) 408-420.

[20] P. Lee, M.M. Swarbrick, K.K.Y. Ho, Brown adipose tissue in adult humans: a metabolic renaissance, Endocr. Rev. 34 (2013) 413-438.

[21] J. Hoerter, M.D.M. Gonzalez-Barroso, E. Couplan, P. Mateo, C. Gelly, A.M. Cassard-Doulcier, P. Diolez, F. Bouillaud, Mitochondrial uncoupling protein 1 expressed in the heart of transgenic mice protects against ischemic-reperfusion damage, Circulation 110 (2004) 528-533.

[22] D.G. Nicholls, Hamster brown-adipose-tissue mitochondria: purine nucleotide control of the ion conductance of the inner membrane, the nature of the nucleotide binding site, Eur. J. Biochem. 62 (1976) 223-228.

[23] G.M. Heaton, R.J. Wagenvoord, A. Kemp, D.G. Nicholls, Brown-adipose-tissue mitochondria: photoaffinity labelling of the regulatory site of energy dissipation, Eur. J. Biochem. 82 (1978) 515-521.

[24] S.G. Huang, Q.S. Lin, M. Klingenberg, Slow-phase kinetics of nucleotide binding to the uncoupling protein from brown adipose tissue mitochondria, J. Biol. Chem. 273 (1998) 859-864.

[25] P. Ježek, J. Houštěk, Z. Drahota, Alkaline pH, membrane potential, and magnesium cations are negative modulators of purine nucleotide inhibition of $\mathrm{H}^{+}$and $\mathrm{Cl}^{-}$transport through the uncoupling protein of brown adipose tissue mitochondria, J. Bioenerg. Biomembr. 20 (1988) 603-622.

[26] P. Ježek, M. Bauer, W.E. Trommer, EPR spectroscopy of 5-DOXYL-stearic acid bound to the mitochondrial uncoupling protein reveals its competitive displacement by alkylsulfonates in the channel and allosteric displacement by ATP, FEBS Lett. 361 (1995) 303-307.

[27] R. Zhu, A. Rupprecht, A. Ebner, T. Haselgrübler, H.J. Gruber, P. Hinterdorfer, E.E. Pohl, Mapping the nucleotide binding site of uncoupling protein 1 using atomic force microscopy, J. Am. Chem. Soc. 135 (2013) 3640-3646.

[28] D.G. Clark, M. Brinkman, S.D. Neville, Microcalorimetric measurements of heat production in brown adipocytes from control and cafeteria-fed rats, Biochem. J. 235 (1986) 337-342.

[29] D. Ricquier, J.L. Gaillard, J.M. Turc, Microcalorimetry of isolated mitochondria from brown adipose tissue effect of guanosine-di-phosphate, FEBS Lett. 99 (1979) 203-206.

[30] L. De Meis, L.A. Ketzer, R.M. Da Costa, I.R. De Andrade, M. Benchimol, Fusion of the endoplasmic reticulum and mitochondrial outer membrane in rats brown adipose tissue: activation of thermogenesis by $\mathrm{Ca}^{2+}$, PLoS One 5 (2010) e9439.

[31] T. Yoneshiro, S. Aita, M. Matsushita, T. Kameya, K. Nakada, Y. Kawai, M. Saito, Brown adipose tissue, whole-body energy expenditure, and thermogenesis in healthy adult men, Obesity 19 (2011) 13-16.

[32] J. Houštěk, P. Tvrdík, S. Pavelka, M. Baudyšová, Low content of mitochondrial ATPase in brown adipose tissue is the result of post-transcriptional regulation, FEBS Lett. 294 (1991) 191-194.

[33] T.V. Kramarova, I.G. Shabalina, U. Andersson, R. Westerberg, I. Carlberg, J. Houstek, J. Nedergaard, B. Cannon, Mitochondrial ATP synthase levels in brown adipose tissue are governed by the c-Fo subunit P1 isoform, FASEB J. 22 (2007) 55-63.

[34] D.G. Nicholls, R.M. Locke, Thermogenic mechanisms in brown fat, Physiol. Rev. 64 (1984) (1 LP-64).

[35] B. Cannon, J. Nedergaard, The biochemistry of an inefficient tissue: brown adipose tissue, Essays Biochem. 20 (1985) 110-164.

[36] E.T. Chouchani, L. Kazak, B.M. Spiegelman, Mitochondrial reactive oxygen species and adipose tissue thermogenesis: bridging physiology and mechanisms, J. Biol. Chem. 292 (2017) 16810-16816.

[37] P. Ježek, M. Žáčková, M. Růžičcka, E. Škobisová, M. Jabůrek, Mitochondrial uncoupling proteins - facts and fantasies, Physiol. Res. 53 (2004) S199-S211.

[38] D.G. Nicholls, Hamster brown-adipose-tissue mitochondria: the control of respiration and the proton electrochemical potential gradient by possible physiological effectors of the proton conductance of the inner membrane, Eur. J. Biochem. 49 (1974) 573-583.

[39] K.D. Garlid, M. Jabůrek, P. Ježek, M. Vařecha, How do uncoupling proteins uncouple? Biochim. Biophys. Acta Bioenerg. 1459 (2000) 383-389.

[40] M. Jabůrek, M. Var̆echa, R.E. Gimeno, M. Dembski, P. Ježek, M. Zhang, P. Burn, L.A. Tartaglia, K.D. Garlid, Transport function and regulation of mitochondrial uncoupling proteins 2 and 3, J. Biol. Chem. 274 (1999) 26003-26007.

[41] M. Jabůrek, K.D. Garlid, Reconstitution of recombinant uncoupling proteins UCP1, -2 , and -3 have similar affinities for ATP and are unaffected by coenzyme Q10, J. Biol. Chem. 278 (2003) 25825-25831.

[42] V. Beck, M. Jabůrek, T. Demina, A. Rupprecht, R.K. Porter, P. Ježek, E.E. Pohl, Polyunsaturated fatty acids activate human uncoupling proteins 1 and 2 in planar lipid bilayers, FASEB J. 21 (2007) 1137-1144.

[43] E. Urbánková, A. Voltchenko, P. Pohl, P. Ježek, E.E. Pohl, Transport kinetics of uncoupling proteins: analysis of UCP1 reconstituted in planar lipid bilayers, J. Biol. Chem. 278 (2003) 32497-32500.

[44] E. Winkler, M. Klingenberg, Effect of fatty acids on $\mathrm{H}^{+}$transport activity of the reconstituted uncoupling protein, J. Biol. Chem. 269 (1994) 2508-2515.

[45] P. Ježek, D.E. Orosz, M. Modriansky, K.D. Garlid, Transport of anions and protons by the mitochondrial uncoupling protein and its regulation by nucleotides and fatty acids: a new look at old hypotheses, J. Biol. Chem. 269 (1994) 26184-26190.

[46] K.D. Garlid, D.E. Orosz, M. Modrianský, S. Vassanelli, P. Ježek, On the mechanism of fatty acid-induced proton transport by mitochondrial uncoupling protein, J. Biol. Chem. 271 (1996) 2615-2620.

[47] V. Beck, M. Jabůrek, E.P. Breen, R.K. Porter, P. Ježek, E.E. Pohl, A new automated technique for the reconstitution of hydrophobic proteins into planar bilayer membranes studies of human recombinant uncoupling protein 1, Biochim. Biophys. Acta Bioenerg. 1757 (2006) 474-479.

[48] A. Fedorenko, P.V. Lishko, Y. Kirichok, Mechanism of fatty-acid-dependent UCP1 uncoupling in brown fat mitochondria, Cell 151 (2012) 400-413.

[49] V.P. Skulachev, Fatty acid circuit as a physiological mechanism of uncoupling of oxidative phosphorylation, FEBS Lett. 294 (1991) 158-162.

[50] K.D. Garlid, M. Jabůrek, P. Ježek, The mechanism of proton transport mediated by mitochondrial uncoupling proteins, FEBS Lett. 438 (1998) 10-14.

[51] K.D. Garlid, M. Jabůrek, P. Ježek, Mechanism of uncoupling protein action, Biochem. Soc. Trans. 29 (2001) 803-806.

[52] M.J. Berardi, J.J. Chou, Fatty acid flippase activity of UCP2 is essential for its proton transport in mitochondria, Cell Metab. 20 (2014) 541-552.

[53] L. Zhao, S. Wang, Q. Zhu, B. Wu, Z. Liu, B. Ouyang, J.J. Chou, Specific interaction of the human mitochondrial uncoupling protein 1 with free long-chain fatty acid, Structure 25 (2017) 1371-1379.e3.

[54] X. Wu, P.A. Gale, Small-molecule uncoupling protein mimics: synthetic anion receptors as fatty acid-activated proton transporters, J. Am. Chem. Soc. 138 (2016) 16508-16514.

[55] P. Ježek, B. Holendová, K.D. Garlid, M. Jabůrek, Mitochondrial uncoupling proteins: subtle regulators of cellular redox signaling, Antioxid. Redox Signal. 29 (2018) 667-714 (ars.2017.7225).

[56] P. Ježek, M. Modrianský, K.D. Garlid, Inactive fatty acids are unable to flip-flop across the lipid bilayer, FEBS Lett. 408 (1997) 161-165.

[57] P. Jezek, M. Modriansky, K.D. Garlid, A structure-activity study of fatty acid interaction with mitochondrial uncoupling protein, FEBS Lett. 408 (1997) 166-170.

[58] M. Jabůrek, M. Vařecha, P. Ježek, K.D. Garlid, Alkylsulfonates as probes of uncoupling protein transport mechanism ion pair transport demonstrates that direct $\mathrm{H}^{+}$translocation by UCP1 is not necessary for uncoupling, J. Biol. Chem. 276 (2001) 31897-31905.

[59] E.P. Breen, W. Pilgrim, K.J. Clarke, C. Yssel, M. Farrell, J. Zhou, P.V. Murphy, R.K. Porter, Lack of activation of UCP1 in isolated brown adipose tissue mitochondria by glucose-O- $\omega$-modified saturated fatty acids of various chain lengths, J. Chem. Biol. 6 (2013) 121-133.

[60] I.G. Shabalina, A.V. Kalinovich, B. Cannon, J. Nedergaard, Metabolically inert perfluorinated fatty acids directly activate uncoupling protein 1 in brown-fat mitochondria, Arch. Toxicol. 90 (2016) 1117-1128.

[61] P. Jezek, K.D. Garlid, New substrates and competitive inhibitors of the Cl- translocating pathway of the uncoupling protein of brown adipose tissue mitochondria, J. Biol. Chem. 265 (1990) 19303-19311.

[62] S. Nouhi, L. Ahrens, H. Campos Pereira, A.V. Hughes, M. Campana, P. Gutfreund, G.K. Palsson, A. Vorobiev, M.S. Hellsing, Interactions of perfluoroalkyl substances with a phospholipid bilayer studied by neutron reflectometry, J. Colloid Interface Sci. 511 (2018) 474-481.

[63] K.S. Echtay, E. Winkler, M. Klingenberg, Coenzyme Q is an obligatory cofactor for uncoupling protein function, Nature 408 (2000) 609-613.

[64] T.C. Esteves, K.S. Echtay, T. Jonassen, C.F. Clarke, M.D. Brand, Ubiquinone is not required for proton conductance by uncoupling protein 1 in yeast mitochondria, Biochem. J. 379 (2004) 309-315.

[65] A. Swida-Barteczka, A. Woyda-Ploszczyca, F.E. Sluse, W. Jarmuszkiewicz, Uncoupling protein 1 inhibition by purine nucleotides is under the control of the endogenous ubiquinone redox state, Biochem. J. 424 (2009) 297-306.

[66] E.T. Chouchani, L. Kazak, M.P. Jedrychowski, G.Z. Lu, B.K. Erickson, J. Szpyt, K.A. Pierce, D. Laznik-Bogoslavski, R. Vetrivelan, C.B. Clish, A.J. Robinson, S.P. Gygi, B.M. Spiegelman, Mitochondrial ROS regulate thermogenic energy expenditure and sulfenylation of UCP1, Nature 532 (2016) 112-116.

[67] F. Kamp, D. Zakim, F. Zhang, N. Noy, J.A. Hamilton, Fatty acid flip-flop in phospholipid bilayers is extremely fast, Biochemistry 34 (1995) 11928-11937.

[68] A.A. Pashkovskaya, M. Vazdar, L. Zimmermann, O. Jovanovic, P. Pohl, E.E. Pohl, Mechanism of long-chain free fatty acid protonation at the membrane-water interface, Biophys. J. 114 (2018) 2142-2151.

[69] P.G. Crichton, Y. Lee, E.R.S. Kunji, The molecular features of uncoupling protein 1 support a conventional mitochondrial carrier-like mechanism, Biochimie 134 (2017) 35-50.

[70] M.J. Berardi, W.M. Shih, S.C. Harrison, J.J. Chou, Mitochondrial uncoupling protein 2 structure determined by NMR molecular fragment searching, Nature 476 (2011) 109-113.

[71] J. Ježek, A. Dlasková, J. Zelenka, M. Jabůrek, P. Ježek, $\mathrm{H}_{2} \mathrm{O}_{2}$-activated mitochondrial phospholipase iPLA2 $\gamma$ prevents lipotoxic oxidative stress in synergy with UCP2, amplifies signaling via G-protein-coupled receptor GPR40, and reg ulates insulin secretion in pancreatic $\beta$-cells, Antioxid. Redox Signal. 23 (2015) 958-972.

[72] M. Jabůrek, J. Ježek, J. Zelenka, P. Ježek, Antioxidant activity by a synergy of redox-sensitive mitochondrial phospholipase A2 and uncoupling protein-2 in lung and spleen, Int. J. Biochem. Cell Biol. 45 (2013) 816-825.

[73] J. Ježek, M. Jabůrek, J. Zelenka, P. Ježek, Mitochondrial phospholipase A2 activated by reactive oxygen species in heart mitochondria induces mild uncoupling, Physiol. Res. 59 (2010) 737-747.

[74] M. Klingenberg, S.G. Huang, Structure and function of the uncoupling protein from brown adipose tissue, Biochim. Biophys. Acta 1415 (1999) 271-296.

[75] Y. Lee, C. Willers, E.R.S. Kunji, P.G. Crichton, Uncoupling protein 1 binds one nucleotide per monomer and is stabilized by tightly bound cardiolipin, Proc. Natl. Acad. Sci. 112 (2015) 6973-6978.

[76] E. Pebay-Peyroula, C. Dahout-Gonzalez, R. Kahn, V. Trézéguet, G.J.-M. Lauquin, G. Brandolin, Structure of mitochondrial ADP/ATP carrier in complex with carboxyatractyloside, Nature 426 (2003) 39-44. 
[77] F. Palmieri, The mitochondrial transporter family SLC25: identification, properties and physiopathology, Mol. Asp. Med. 34 (2013) 465-484.

[78] W. Sun, C. Liu, Q. Chen, N. Liu, Y. Yan, B. Liu, SIRT3: a new regulator of cardiovascular diseases, Oxidative Med. Cell. Longev. 2018 (2018) 1-11.

[79] Y. Zhang, S.S. Bharathi, M.J. Rardin, J. Lu, K.V. Maringer, S. Sims-Lucas, E.V. Prochownik, B.W. Gibson, E.S. Goetzman, Lysine desuccinylase SIRT5 binds to cardiolipin and regulates the electron transport chain, J. Biol. Chem. 292 (2017) 10239-10249.

[80] M.J. Rardin, W. He, Y. Nishida, J.C. Newman, C. Carrico, S.R. Danielson, A. Guo, P. Gut, A.K. Sahu, B. Li, R. Uppala, M. Fitch, T. Riiff, L. Zhu, J. Zhou, D. Mulhern, R.D. Stevens, O.R. Ilkayeva, C.B. Newgard, M.P. Jacobson, et al., SIRT5 regulates the mitochondrial lysine succinylome and metabolic networks, Cell Metab. 18 (2013) 920-933.

[81] K.A. Anderson, F.K. Huynh, K. Fisher-Wellman, J.D. Stuart, B.S. Peterson, J.D. Douros, G.R. Wagner, J.W. Thompson, A.S. Madsen, M.F. Green, R.M. Sivley, O.R. Ilkayeva, R.D. Stevens, D.S. Backos, J.A. Capra, C.A. Olsen, J.E. Campbell, D.M. Muoio, P.A. Grimsrud, M.D. Hirschey, SIRT4 is a lysine deacylase that controls leucine metabolism and insulin secretion, Cell Metab. 25 (2017) 838-855.e15.

[82] K.A. Smith, G.B. Waypa, P.T. Schumacker, Redox signaling during hypoxia in mammalian cells, Redox Biol. 13 (2017) 228-234.

[83] L. Plecitá-Hlavatá, P. Ježek, Integration of superoxide formation and cristae morphology for mitochondrial redox signaling, Int. J. Biochem. Cell Biol. 80 (2016) 31-50.

[84] K.M. Davies, M. Strauss, B. Daum, J.H. Kief, H.D. Osiewacz, A. Rycovska, V. Zickermann, W. Kuhlbrandt, Macromolecular organization of ATP synthase and complex I in whole mitochondria, Proc. Natl. Acad. Sci. 108 (2011) 14121-14126.

[85] K. Mahdaviani, I.Y. Benador, S. Su, R.A. Gharakhanian, L. Stiles, K.M. Trudeau, M. Cardamone, V. Enríquez-Zarralanga, E. Ritou, T. Aprahamian, M.F. Oliveira, B.E. Corkey, V. Perissi, M. Liesa, O.S. Shirihai, Mfn2 deletion in brown adipose tissue protects from insulin resistance and impairs thermogenesis, EMBO Rep. 18 (2017) 1123-1138

[86] M. Liesa, O.S. Shirihai, Mitochondrial dynamics in the regulation of nutrient utilization and energy expenditure, Cell Metab. 17 (2013) 491-506.

[87] E. Klotzsch, A. Smorodchenko, L. Löfler, R. Moldzio, E. Parkinson, G.J. Schütz, E.E. Pohl, Superresolution microscopy reveals spatial separation of UCP4 and $\mathrm{F}_{0} \mathrm{~F}_{1}$-ATP synthase in neuronal mitochondria, Proc. Natl. Acad. Sci. 112 (2015) $130-135$.

[88] T. Hoang, M.D. Smith, M. Jelokhani-Niaraki, Toward understanding the mechanism of ion transport activity of neuronal uncoupling proteins UCP2, UCP4, and UCP5, Biochemistry 51 (2012) 4004-4014.

[89] C.M. Anderson, M. Kazantzis, J. Wang, S. Venkatraman, R.L.S. Goncalves, C.L. Quinlan, R. Ng, M. Jastroch, D.I. Benjamin, B. Nie, C. Herber, A.A.N. Van, M.J. Park, D. Yun, K. Chan, A. Yu, P. Vuong, M. Febbraio, D.K. Nomura, J.L. Napoli, et al., Dependence of brown adipose tissue function on CD36-mediated coenzyme Q uptake, Cell Rep. 10 (2015) 505-515.

[90] A. Lombardi, R. Senese, R. De Matteis, R.A. Busiello, F. Cioffi, F. Goglia, A. Lanni, 3,5-diiodo-L-thyronine activates brown adipose tissue thermogenesis in hypothyroid rats, PLoS One 10 (2015) e0116498.

[91] S. Enerbäck, A. Jacobsson, E.M. Simpson, C. Guerra, H. Yamashita, M.-E. Harper, L.P. Kozak, Mice lacking mitochondrial uncoupling protein are cold-sensitive but not obese, Nature 387 (1997) 90-94.

[92] V. Golozoubova, Only UCP1 can mediate adaptive nonshivering thermogenesis in the cold, FASEB J. 15 (2001) 2048-2050.

[93] V. Golozoubova, B. Cannon, J. Nedergaard, UCP1 is essential for adaptive adrenergic nonshivering thermogenesis, Am. J. Physiol. Endocrinol. Metab. 291 (2006) E350-E357.

[94] H.M. Feldmann, V. Golozoubova, B. Cannon, J. Nedergaard, UCP1 ablation induces obesity and abolishes diet-induced thermogenesis in mice exempt from thermal stress by living at thermoneutrality, Cell Metab. 9 (2009) 203-209.

[95] L.S. Hoffmann, J. Etzrodt, L. Willkomm, A. Sanyal, L. Scheja, A.W.C. Fischer, J. P. Stasch, W. Bloch, A. Friebe, J. Heeren, A. Pfeifer, Stimulation of soluble guanylyl cyclase protects against obesity by recruiting brown adipose tissue, Nat. Commun. 6 (2015) 7235.

[96] G. Godlewski, T. Jourdan, G. Szanda, J. Tam, J. Resat Cinar, J. Harvey-White, B. Liu, P. Mukhopadhyay, F. Pacher, Ming Mo, D. Osei-Hyiaman, George Kunos, Mice lacking GPR3 receptors display late-onset obese phenotype due to impaired thermogenic function in brown adipose tissue, Sci. Rep. 5 (2015) 14953.

[97] S. Kooijman, Y. Wang, E.T. Parlevliet, M.R. Boon, D. Edelschaap, G. Snaterse, H. Pijl, J.A. Romijn, P.C.N. Rensen, Central GLP-1 receptor signalling accelerates plasma clearance of triacylglycerol and glucose by activating brown adipose tissue in mice, Diabetologia 58 (2015) 2637-2646.

[98] F. Villarroya, M. Peyrou, M. Giralt, Transcriptional regulation of the uncoupling protein-1 gene, Biochimie 134 (2017) 86-92.

[99] P. Seale, B. Bjork, W. Yang, S. Kajimura, S. Chin, S. Kuang, A. Scimè S. Devarakonda, H.M. Conroe, H. Erdjument-Bromage, P. Tempst, M.A. Rudnicki, D.R. Beier, B.M. Spiegelman, PRDM16 controls a brown fat/skeletal muscle switch, Nature 454 (2008) 961-967.

[100] M.J. Betz, S. Enerbäck, Human brown adipose tissue: what we have learned so far, Diabetes 64 (2015) 2352-2360.

[101] S.Y. Shi, W. Zhang, C.T. Luk, T. Sivasubramaniyam, J.J. Brunt, S.A. Schroer, H.R. Desai, A. Majerski, M. Woo, JAK2 promotes brown adipose tissue function and is required for diet- and cold-induced thermogenesis in mice, Diabetologia 59 (2016) 187-196.

[102] M. Boutant, M. Joffraud, S.S. Kulkarni, E. García-Casarrubios, P.M. García-Roves, J. Ratajczak, P.J. Fernández-Marcos, A.M. Valverde, M. Serrano, C. Cantó, SIRT1 enhances glucose tolerance by potentiating brown adipose tissue function, Mol. Metab. 4 (2015) 118-131.

[103] J.I. Odegaard, M.-W. Lee, Y. Sogawa, A.M. Bertholet, R.M. Locksley, D.E. Weinberg, Y. Kirichok, R.C. Deo, A. Chawla, Perinatal licensing of thermo genesis by IL-33 and ST2, Cell 171 (2017) 1707.

[104] J. Wu, P. Boström, L.M. Sparks, L. Ye, J.H. Choi, A.H. Giang, M. Khandekar, K.A. Virtanen, P. Nuutila, G. Schaart, K. Huang, H. Tu, W.D. Van Marken Lichtenbelt, J. Hoeks, S. Enerbäck, P. Schrauwen, B.M. Spiegelman, Beige adipocytes are a distinct type of thermogenic fat cell in mouse and human, Cell 150 (2012) 366-376.

[105] K. Ikeda, P. Maretich, S. Kajimura, The common and distinct features of brown and beige adipocytes, Trends Endocrinol. Metab. 29 (2018) 191-200.

[106] S.Y. Min, J. Kady, M. Nam, R. Rojas-Rodriguez, A. Berkenwald, J.H. Kim, H.L. Noh, J.K. Kim, M.P. Cooper, T. Fitzgibbons, M.A. Brehm, S. Corvera, Human "brite/beige" adipocytes develop from capillary networks, and their implantation improves metabolic homeostasis in mice, Nat. Med. 22 (2016) 312-318.

[107] Q. Zheng, J. Lin, J. Huang, H. Zhang, R. Zhang, X. Zhang, C. Cao, C. Hambly, G. Qin, J. Yao, R. Song, Q. Jia, X. Wang, Y. Li, N. Zhang, Z. Piao, R. Ye, J.R. Speakman, H. Wang, Q. Zhou, et al., Reconstitution of UCP1 using CRISPR/ Cas9 in the white adipose tissue of pigs decreases fat deposition and improves thermogenic capacity, Proc. Natl. Acad. Sci. 114 (2017) (201707853).

[108] K.-J. Chung, A. Chatzigeorgiou, M. Economopoulou, R. Garcia-Martin, V.I. Alexaki, I. Mitroulis, M. Nati, J. Gebler, T. Ziemssen, S.E. Goelz, J. Phieler, J,H. Lim, K.P. Karalis, T. Papayannopoulou, M. Blüher, G. Hajishengallis, T. Chavakis, A self-sustained loop of inflammation-driven inhibition of beige adipogenesis in obesity, Nat. Immunol. 18 (2017) 654-664.

[109] M. Keuper, S. Sachs, E. Walheim, L. Berti, B. Raedle, D. Tews, P. FischerPosovszky, M. Wabitsch, M. Hrabě de Angelis, G. Kastenmüller, M.H. Tschöp, M. Jastroch, H. Staiger, S.M. Hofmann, Activated macrophages control human adipocyte mitochondrial bioenergetics via secreted factors, Mol. Metab. 6 (2017) $1226-1239$.

[110] K. Klepac, A. Kilić, T. Gnad, L.M. Brown, B. Herrmann, A. Wilderman, A. Balkow, A. Glöde, K. Simon, M.E. Lidell, M.J. Betz, S. Enerbäck, J. Wess, M. Freichel, M. Blüher, G. König, E. Kostenis, P.A. Insel, A. Pfeifer, The Gq signalling pathway inhibits brown and beige adipose tissue, Nat. Commun. 7 (2016) 10895.

[111] M. Rosenwald, A. Perdikari, T. Rülicke, C. Wolfrum, Bi-directional interconversion of brite and white adipocytes, Nat. Cell Biol. 15 (2013) 659-667.

[112] M. Harms, P. Seale, Brown and beige fat: development, function and therapeutic potential, Nat. Med. 19 (2013) 1252-1263.

[113] Y. Qiu, K.D. Nguyen, J.I. Odegaard, X. Cui, X. Tian, R.M. Locksley, R.D. Palmiter, A. Chawla, Eosinophils and type 2 cytokine signaling in macrophages orchestrate development of functional beige fat, Cell 157 (2014) 1292-1308.

[114] A.M. Bertholet, L. Kazak, E.T. Chouchani, M.G. Bogaczyńska, I. Paranjpe, G.L. Wainwright, A. Bétourné, S. Kajimura, B.M. Spiegelman, Y. Kirichok, Mitochondrial patch clamp of beige adipocytes reveals UCP1-positive and UCP1negative cells both exhibiting futile creatine cycling, Cell Metab. 25 (2017) 811-822.e4.

[115] W.J. Laursen, M. Mastrotto, D. Pesta, O.H. Funk, J.B. Goodman, D.K. Merriman, N. Ingolia, G.I. Shulman, S.N. Bagriantsev, E.O. Gracheva, Neuronal UCP1 expression suggests a mechanism for local thermogenesis during hibernation, Proc. Natl. Acad. Sci. U. S. A. 112 (2014) 1-6.

[116] S. Enerbäck, Brown adipose tissue in humans, Int. J. Obes. 34 (2010) S43-S46.

[117] J. Houštěk, K. Vízek, S. Pavelka, J. Kopecký, E. Krejčová, J. Heřmanská, M. Čermáková, Type II iodothyronine 5'-deiodinase and uncoupling protein in brown adipose tissue of human newborns, J. Clin. Endocrinol. Metab. 77 (1993) 382-387.

[118] J. Nedergaard, T. Bengtsson, B. Cannon, Unexpected evidence for active brown adipose tissue in adult humans, Am. J. Physiol. Endocrinol. Metab. 293 (2007) E444-E452.

[119] A.M. Cypess, S. Lehman, G. Williams, I. Tal, D. Rodman, A.B. Goldfine, F.C. Kuo, E.L. Palmer, Y.H. Tseng, A. Doria, G.M. Kolodny, C. Ronald Kahn, Identification and importance of brown adipose tissue in adult humans, Obstet. Gynecol. Surv. 64 (2009) 519-520.

[120] M. Saito, Y. Okamatsu-Ogura, M. Matsushita, K. Watanabe, T. Yoneshiro, J. NioKobayashi, T. Iwanaga, M. Miyagawa, T. Kameya, K. Nakada, Y. Kawai, M. Tsujisaki, High incidence of metabolically active brown adipose tissue in healthy adult humans: effects of cold exposure and adiposity, Diabetes 58 (2009) 1526-1531.

[121] K.A. Virtanen, M.E. Lidell, J. Orava, M. Heglind, R. Westergren, T. Niemi, M. Taittonen, J. Laine, N.-J. Savisto, S. Enerbäck, P. Nuutila, Functional brown adipose tissue in healthy adults, N. Engl. J. Med. 360 (2009) 1518-1525.

[122] T. Nishimura, T. Katsumura, M. Motoi, H. Oota, S. Watanuki, Experimental evidence reveals the UCP1 genotype changes the oxygen consumption attributed to non-shivering thermogenesis in humans, Sci. Rep. 7 (2017) 5570.

[123] O. Muzik, T.J. Mangner, W.R. Leonard, A. Kumar, J. Janisse, J.G. Granneman, ${ }^{15} \mathrm{O}$ PET measurement of blood flow and oxygen consumption in cold-activated human brown fat, J. Nucl. Med. 54 (2013) 523-531.

[124] M. U Din, J. Raiko, T. Saari, N. Kudomi, T. Tolvanen, V. Oikonen, J. Teuho, H.T. Sipilä, N. Savisto, R. Parkkola, P. Nuutila, K.A. Virtanen, Human brown adipose tissue $\left[{ }^{15} \mathrm{O}\right] \mathrm{O}_{2}$ PET imaging in the presence and absence of cold stimulus, Eur. J. Nucl. Med. Mol. Imaging 43 (2016) 1878-1886.

[125] C. Porter, D.N. Herndon, M. Chondronikola, T. Chao, P. Annamalai, N. Bhattarai, M.K. Saraf, K.D. Capek, P.T. Reidy, A.C. Daquinag, M.G. Kolonin, B.B. Rasmussen, E. Borsheim, T. Toliver-Kinsky, L.S. Sidossis, Human and mouse brown adipose tissue mitochondria have comparable UCP1 function, Cell Metab. 24 (2016) 246-255. 
[126] M. Chondronikola, E. Volpi, E. Børsheim, C. Porter, M.K. Saraf, P. Annamalai, C. Yfanti, T. Chao, D. Wong, K. Shinoda, S.M. Labbe, N.M. Hurren, F. Cesani, S. Kajimura, L.S. Sidossis, Brown adipose tissue activation is linked to distinct systemic effects on lipid metabolism in humans, Cell Metab. 23 (2016) 1200-1206.

[127] M. Chondronikola, E. Volpi, E. Børsheim, C. Porter, P. Annamalai, S. Enerbäck, M.E. Lidell, M.K. Saraf, S.M. Labbe, N.M. Hurren, C. Yfanti, T. Chao, C.R. Andersen, F. Cesani, H. Hawkins, L.S. Sidossis, Brown adipose tissue improves whole-body glucose homeostasis and insulin sensitivity in humans, Diabetes 63 (2014) 4089-4099.

[128] L.S. Sidossis, C. Porter, M.K. Saraf, E. Børsheim, R.S. Radhakrishnan, T. Chao, A. Ali, M. Chondronikola, R. Mlcak, C.C. Finnerty, H.K. Hawkins, T. ToliverKinsky, D.N. Herndon, Browning of subcutaneous white adipose tissue in humans after severe adrenergic stress, Cell Metab. 22 (2015) 219-227.

[129] P. Lee, J.D. Linderman, S. Smith, R.J. Brychta, J. Wang, C. Idelson, R.M. Perron, C.D. Werner, G.Q. Phan, U.S. Kammula, E. Kebebew, K. Pacak, K.Y. Chen, F.S. Celi, Irisin and FGF21 are cold-induced endocrine activators of brown fat function in humans, Cell Metab. 19 (2014) 302-309.

[130] M.K. Hankir, M. Kranz, T. Gnad, J. Weiner, S. Wagner, W. Deuther-Conrad, F. Bronisch, K. Steinhoff, J. Luthardt, N. Klöting, S. Hesse, J.P. Seibyl, O. Sabri, J.T. Heiker, M. Blüher, A. Pfeifer, P. Brust, W.K. Fenske, A novel thermoregulatory role for PDE10A in mouse and human adipocytes, EMBO Mol. Med. 8 (2016) 796-812.

[131] N. Matesanz, E. Bernardo, R. Acín-Pérez, E. Manieri, S. Pérez-Sieira, L. HernándezCosido, V. Montalvo-Romeral, A. Mora, E. Rodríguez, L. Leiva-Vega, A.V. LechugaVieco, J. Ruiz-Cabello, J.L. Torres, M. Crespo-Ruiz, F. Centeno, C.V. Álvarez, M. Marcos, J.A. Enríquez, R. Nogueiras, G. Sabio, MKK6 controls T3-mediated browning of white adipose tissue, Nat. Commun. 8 (2017) 856.

[132] J. Delás, M. Notari, J. Forés, J. Pechuan, M. Porcar, E. Navarro, A. Montagud, M. Baguena, J. Peretó, P.F. de Córdoba, M.M. González-Barroso, E. Rial, A. Moya, J. Urchueguía, P.F. de Córdoba, M.M. González-Barroso, E. Rial, A. Moya, J. Urchueguía, Yeast cultures with UCP1 uncoupling activity as a heating device, New Biotechnol. 26 (2009) 300-306.

[133] D. Chrétien, P. Bénit, H.H. Ha, S. Keipert, R. El-Khoury, Y.T. Chang, M. Jastroch, H.T. Jacobs, P. Rustin, M. Rak, Mitochondria are physiologically maintained at close to $50{ }^{\circ} \mathrm{C}$, PLoS Biol. 16 (2018) e2003992.

[134] P. Ježek, H.J. Freisleben, Fatty acid binding site of the mitochondrial uncoupling protein demonstration of its existence by EPR spectroscopy of 5-DOXYL-stearic acid, FEBS Lett. 343 (1994) 22-26.

[135] M. Klingenberg, UCP1 - a sophisticated energy valve, Biochimie 134 (2017) 19-27.

[136] E. Winkler, E. Wachter, M. Klingenberg, Identification of the $\mathrm{pH}$ sensor for nucleotide binding in the uncoupling protein from brown adipose tissue, Biochemistry 36 (1997) 148-155.

[137] H. Yoo, M.R. Antoniewicz, G. Stephanopoulos, J.K. Kelleher, Quantifying reductive carboxylation flux of glutamine to lipid in a brown adipocyte cell line, J. Biol. Chem. 283 (2008) 20621-20627.

[138] R. Oelkrug, N. Goetze, C.W. Meyer, M. Jastroch, Antioxidant properties of UCP1 are evolutionarily conserved in mammals and buffer mitochondrial reactive oxygen species, Free Radic. Biol. Med. 77 (2014) 210-216.

[139] K.J. Clarke, R.K. Porter, Uncoupling protein 1 dependent reactive oxygen species production by thymus mitochondria, Int. J. Biochem. Cell Biol. 45 (2013) 81-89.

[140] I.G. Shabalina, M. Vrbacký, A. Pecinová, A.V. Kalinovich, Z. Drahota, J. Houšsěk, T. Mráček, B. Cannon, J. Nedergaard, ROS production in brown adipose tissue mitochondria: the question of UCP1-dependence, Biochim. Biophys. Acta Bioenerg. 1837 (2014) 2017-2030.

[141] A.M. Carroll, R.K. Porter, N.A. Morrice, Identification of serine phosphorylation in mitochondrial uncoupling protein 1, Biochim. Biophys. Acta Bioenerg. 1777 (2008) 1060-1065.

[142] K.J. Clarke, A.E. Adams, L.H. Manzke, T.W. Pearson, C.H. Borchers, R.K. Porter, A role for ubiquitinylation and the cytosolic proteasome in turnover of mitochondrial uncoupling protein 1 (UCP1), Biochim. Biophys. Acta Bioenerg. 1817 (2012) 1759-1767.

[143] M.D. Brand, Mitochondrial generation of superoxide and hydrogen peroxide as the source of mitochondrial redox signaling, Free Radic. Biol. Med. 100 (2016) 14-31.

[144] A. Dlasková, K.J. Clarke, R.K. Porter, The role of UCP 1 in production of reactive oxygen species by mitochondria isolated from brown adipose tissue, Biochim. Biophys. Acta Bioenerg. 1797 (2010) 1470-1476.

[145] R. Oelkrug, M. Kutschke, C.W. Meyer, G. Heldmaier, M. Jastroch, Uncoupling protein 1 decreases superoxide production in brown adipose tissue mitochondria, J. Biol. Chem. 285 (2010) 21961-21968.

[146] E.A. Malingriaux, A. Rupprecht, L. Gille, O. Jovanovic, P. Ježek, M. Jabůrek, E.E. Pohl, Fatty acids are key in 4-hydroxy-2-nonenal-mediated activation of uncoupling proteins 1 and 2, PLoS One 8 (2013) e77786.

[147] I.G. Shabalina, J. Hoeks, T.V. Kramarova, P. Schrauwen, B. Cannon, J. Nedergaard, Cold tolerance of UCP1-ablated mice: a skeletal muscle mitochondria switch toward lipid oxidation with marked UCP3 up-regulation not associated with increased basal, fatty acid- or ROS-induced uncoupling or enhanced GDP effects, Biochim. Biophys. Acta Bioenerg. 1797 (2010) 968-980.

[148] M. Nabben, I.G. Shabalina, E. Moonen-Kornips, D. Van Beurden, B. Cannon, P. Schrauwen, J. Nedergaard, J. Hoeks, Uncoupled respiration, ROS production, acute lipotoxicity and oxidative damage in isolated skeletal muscle mitochondria from UCP3-ablated mice, Biochim. Biophys. Acta Bioenerg. 1807 (2011) 1095-1105.

[149] O. Jovanovic, A.A. Pashkovskaya, A. Annibal, M. Vazdar, N. Burchardt, A. Sansone, L. Gille, M. Fedorova, C. Ferreri, E.E. Pohl, The molecular mechanism behind reactive aldehyde action on transmembrane translocations of proton and potassium ions, Free Radic. Biol. Med. 89 (2015) 1067-1076.

[150] L. Kazak, E.T. Chouchani, I.G. Stavrovskaya, G.Z. Lu, M.P. Jedrychowski, D.F. Egan, M. Kumari, X. Kong, B.K. Erickson, J. Szpyt, E.D. Rosen, M.P. Murphy, B.S. Kristal, S.P. Gygi, B.M. Spiegelman, UCP1 deficiency causes brown fat respiratory chain depletion and sensitizes mitochondria to calcium overload-induced dysfunction, Proc. Natl. Acad. Sci. 114 (2017) 7981-7986.

[151] A. Frontini, S. Rousset, A.M. Cassard-Doulcier, C. Zingaretti, D. Ricquier, S. Cinti, Thymus uncoupling protein 1 is exclusive to typical brown adipocytes and is not found in thymocytes, J. Histochem. Cytochem. 55 (2007) 183-189.

[152] A.E. Adams, A.M. Carroll, P.G. Fallon, R.K. Porter, Mitochondrial uncoupling protein 1 expression in thymocytes, Biochim. Biophys. Acta Bioenerg. 1777 (2008) $772-776$.

[153] A.E. Adams, O.M. Kelly, R.K. Porter, Absence of mitochondrial uncoupling protein 1 affects apoptosis in thymocytes, thymocyte/T-cell profile and peripheral T-cell number, Biochim. Biophys. Acta Bioenerg. 1797 (2010) 807-816. 